\title{
Factors Influencing Medical Students' Experiences and Satisfaction with Blended Integrated E-Learning
}

\author{
Shashidhar Venkatesh ${ }^{a}$ Yeshwanth K. Rao ${ }^{b}$ Haleagrahara Nagaraja ${ }^{a}$ \\ Torres Woolley $^{\mathrm{a}}$ Faith O. Alele ${ }^{\mathrm{a}}$ Bunmi S. Malau-Adulia \\ a Division of Tropical Health and Medicine, College of Medicine and Dentistry, James Cook University, \\ Townsville, QLD, Australia; b Saint James School of Medicine, The Quarter, Anguilla
}

\section{Significance of the Study}

- Students' satisfaction with blended integrated learning (BIL) is influenced by student characteristics, environmental, and cognitive factors.

- Factors that influence learners' satisfaction with BIL are gender, performance expectation, and learning climate.

- Social interaction is an important component in ensuring perceived satisfaction with BIL.

\section{Keywords}

Blended learning · Learner satisfaction · E-Learning ·

Medical education

\begin{abstract}
Objectives: Blended learning has been presented as a promising learner-centred model that emphasises the learning outcome rather than the process of education, but it can negatively affect learners' engagement with learning. Subject and Methods: Using a mixed-methods approach, this study aimed to determine the significant predictors of learning satisfaction and to evaluate the experiences of medical students with the different domains of an introduced blended integrated learning approach. Results: The survey was administered to 92 respondents with a mean age of 20.5 years. Male students had significantly higher computer selfefficacy and overall learner satisfaction ratings than their female counterparts. Multiple regression analysis showed that
\end{abstract}

\begin{tabular}{ll}
\hline KARGER & $\begin{array}{l}\text { C) } 2019 \text { The Author(s) } \\
\text { Published by S. Karger AG, Basel }\end{array}$ \\
karger@karger.com & This is an Open Access article licensed under the Creative Commons \\
www.karger.com/mpp & $\begin{array}{l}\text { Attribution-NonCommercial-4.0 International License (CC BY-NC) } \\
\text { (http://www.karger.com/Services/OpenAccessLicense), applicable to } \\
\text { the online version of the article only. Usage and distribution for com- } \\
\text { mercial purposes requires written permission. }\end{array}$
\end{tabular}

gender (student characteristics), performance expectations (cognitive factors), and learning climate (social environment) were predictors of the perceived satisfaction of learners. Conclusion: Wider integration of blended learning into pre-clinical undergraduate medical education could enhance the shift towards competency-based education and life-long learning among medical students. However, effective implementation would depend largely on student characteristics, as well as environmental and cognitive components of the delivery method. @ 2019 The Author(s)

Published by S. Karger AG, Basel

\section{Introduction}

Integration of basic science and clinical concepts throughout the curriculum helps students to develop clinical reasoning skills [1]. It also fosters knowledge retention and reinforces the relevance and application of 
basic sciences to clinical context [2]. On this premise, and with the emphasis on competency-based medical education, educators have had to adopt a learner-centred model using diverse teaching methods to aid effective teaching and learning processes [3].

In this learner-centred paradigm, educators are encouraged to serve as facilitators of learning rather than sole distributors of content knowledge [4]. Technologyenhanced interactive learning (also known as e-learning) allows learning to be individualised, enhances collaborative learning, and realigns the educator's role from disseminator to facilitator of the learning process [5]. Elearning has been shown to be more efficient than traditional educator-led methods of learning because it fosters learner intuitiveness and adaptability of learning style, and these translate into improved motivation and performance $[6,7]$. Interestingly, e-learning is viewed by learners as a complement rather than as a substitute for the traditional educator-led teaching method [8]. It therefore serves as part of a blended learning system that combines e-learning technology with traditional educator-led teaching [7].

Blended learning provides a learning delivery approach that alludes to the adult learning theoretical framework which relates to practical application of new learning to past experiences and fosters life-long learning [9]. Previous studies have reported using the blended learning approach to deliver courses such as Anatomy and Physiology to students [10-12]. In these studies, students reported satisfaction with the content and mode of delivery of the courses [10-12]. Furthermore, students' performance in examinations were reported to have improved with the blended learning approach compared to traditional faceto-face lectures [12]. Although blended learning is considered beneficial, students have reported a perceived higher workload $[10,11]$. Within the context of blended learning, previous studies have revealed that computer self-efficacy and performance expectations are cognitive determinants of behaviour and that they are positively correlated to learner satisfaction $[13,14]$. Additionally, environmental factors such as system functionality, content feature (technological environment) as well as social interactions and collaborative learning (social environment) affect the perceived usefulness of blended learning [15]. Assessing contexts for effective use of e-learning in medical education has been reported as an area that warrants research [6]. Given the importance of curriculum integration in medical education, we hypothesised that blended learning can serve as an effective teaching and learning strategy to foster integration, application, and relevance of basic scienc- es to clinical contexts, with enhanced student satisfaction. However, for blended learning to be effective in medical education, it is important to understand the factors that influence learner satisfaction.

In this study, we aimed to determine the factors influencing learner satisfaction with blended integrated learning (BIL) and to explore the learners' perceptions of the impact of BIL on their learning process.

\section{Subjects and Methods}

\section{Educational Context and Curriculum}

The first three (pre-clinical) years of the James Cook University (JCU) medical curriculum provides a system-based introduction to the foundations of medicine. Students are enrolled in two chained subjects for each academic year, and within each subject, there are 4-5 modules. However, horizontal integration of the basic science modules has been difficult. To ensure horizontal integration and a balanced ratio of teaching staff to student, a re-evaluation of the delivery of content material was conducted. Year-2 teaching staff from Physiology, Pathology, and Pharmacology codeveloped and embedded content material for 1 week of teaching within an integrated blended learning environment in the Blackboard learning platform. This mode of teaching/learning was embedded in one of the preclinical Year-2 modules - Haematology and Renal Medicine (HRM), which is a component of the subject Integrated Human System Pathophysiology. Integrated Human System Pathophysiology is the first part of a subject chain in the second year. This subject provides foundation knowledge of anatomy and physiology and common pathophysiology of body systems. This subject comprises four modules, namely Cardiovascular Medicine; Haematology and Renal Medicine; Respiratory Medicine; and Rural, Remote, Indigenous, and Tropical Health.

In the HRM module, students explored the anatomy, physiology, pathophysiology, and immunology relating to haematological systems. Students were first given didactic lectures (traditional teaching session) on components of Blood, Haemopoietic system, and Haemostasis. The didactic sessions comprised lectures on the topics, guided learning sessions (group activities, solving teachercreated questions, cases, and microscopy tutorials), and a synthesis session to consolidate learning. A quiz was administered at the end of the traditional teaching sessions. Subsequently, the topic "Haemostatic disorders" was covered using a BIL approach by a multidisciplinary team of four experts (Physiologist, Pathologist, Pharmacologist, and Clinician). The topic "Haemostatic disorders" was presented by the teaching staff with an emphasis on integrated pathophysiology; i.e., clinical application of physiology concepts, to understand patient presentations with haematopoietic disorders.

\section{Participants}

The study was conducted in February 2016 at James Cook University (JCU). All Year-2 medical students (183 students) were exposed to the teaching sessions in week 3; all students were invited to provide feedback on their experiences of the BIL teaching method. Students were assured of no adverse academic repercussions for non-participation. Consenting students completed the survey instrument after the synthesising session. 
Table 1. Correlations and reliabilities among BIL dimensions

\begin{tabular}{|c|c|c|c|c|c|c|c|}
\hline Dimension & 1 & 2 & 3 & 4 & 5 & 6 & 7 \\
\hline Learner satisfaction & $1(0.96)$ & & & & & & \\
\hline Computer self-efficacy & $0.68^{* * *}$ & $1(0.88)$ & & & & & \\
\hline Performance expectations & $0.88^{* * *}$ & $0.67^{* * *}$ & $1(0.89)$ & & & & \\
\hline System functionality & $0.73^{* * *}$ & $0.58^{* * *}$ & $0.72^{* * *}$ & $1(0.86)$ & & & \\
\hline Content features & $0.70^{* * *}$ & $0.57^{* * *}$ & $0.69^{* * *}$ & $0.74^{* * *}$ & $1(0.83)$ & & \\
\hline
\end{tabular}

\section{Blended Learning Design}

For the BIL sessions, documents containing the weekly learning outcomes and learning resources were uploaded onto the Blackboard learning management system, and students were given an introductory lecture on the topic and an overview of blended learning. BIL sessions comprised multiple online interactive videos (12-15 min each with a total time of 60-80 min) with built-in questions to emphasise the underlying basic and clinical science concepts and their relevance. The videos contained clinical case presentations, images, digital microscopy slides and laboratory reports and were made available both via Blackboard learning management system and Yammer social network. Embedded video questions tested students' knowledge about the diagnosis and physiology behind the signs and symptoms and laboratory reports. At the end of the BIL sessions, a 1-h synthesising session, which involved an integrated lecture-based review of the learning activities was provided to the students with a question/answer and discussion time. Another quiz was administered to the students at the end of the BIL teaching sessions.

\section{Quantitative and Qualitative Data}

A pre-validated survey tool comprising 21 close-ended questions on a seven-point Likert scale [16] was used to measure students' satisfaction with BIL. Three open-ended questions were used to explore students' experiences with and perceptions of the BIL method. The questionnaire assessed the participants' perceptions of the BIL setup and their learning experience in seven domains - computer self-efficacy, performance expectations, system functionality, content features, interaction, learning climate, and learner satisfaction. The survey was administered in class to optimise the response rate. To ensure power balance, the survey was administered by researchers who were not involved in teaching and assessing the students. Students' demographics (gender, age, and origin status) were extracted from the University's Student Record System and cross-referenced with the survey responses to examine the effect of these variables on the level of satisfaction.

\section{Statistical Analysis}

The quantitative data was analysed using SPSS version 25. A Mann-Whitney $U$ test was performed to assess the association between demographic variables (age, gender, and origin) and learner satisfaction. A multiple regression analysis was conducted to de- termine the relationship between the variables age, gender, student status, and learning experience domains and learning satisfaction. Assumptions for linearity, normality of residuals, multicollinearity, and homoscedasticity were met. The internal consistency of the survey items was assessed using reliability analysis, and the associations between the data variables were examined using Pearson's correlation analysis. Students' mean scores on the assessment items (on-line quizzes) were analysed using a non-parametric Mann-Whitney test. The level of significance was set at 0.05 .

For the qualitative data analysis, emerging themes from the open-ended survey questions were identified using a constant comparison process, as advocated by Strauss and Corbin [17]. Illustrative quotes are reported verbatim to support the discussion.

\section{Results}

All Year-2 students (183) participated in the teaching sessions, while 92 (50\%) participated in the survey. The mean age of the study participants was 20.5 years (SD $4.1) ; 58 \%$ of the study participants were female, and $85 \%$ were domestic students. The sampled population is similar to the Year-2 student cohort profile, indicating a representative sample. The analysis of students' performances in the 25 MCQ quiz items showed statistically significant differences $(p<0.0025)$ in the mean scores. The students obtained significantly higher mean scores $(59.86 \pm 0.14 ; 95 \% \mathrm{CI}=0.34-0.51)$ in the post-BIL quiz in comparison to the post-traditional teaching quiz $(42.52 \pm 0.21 ; 95 \% \mathrm{CI}=0.54-0.66)$.

In relation to our first research question (what factors influence leaner satisfaction with BIL?), learner satisfaction was highly and positively correlated to all other variables with Pearson coefficient ranging from $0.68-$ 0.88 (Table 1). The highly correlated domains were performance expectations and learning climate, while computer self-efficacy and interaction had the weakest positive relationship with learner satisfaction. System 
Table 2. Regression variables for learner satisfaction

\begin{tabular}{lrrrrr}
\hline Variables & $\beta$ & $\mathrm{SE}_{\mathrm{B}}$ & $\mathrm{B}$ & $t$ & $p$ \\
\hline Age & 0.208 & 0.199 & 0.045 & 1.044 & 0.300 \\
Gender & 0.453 & 0.152 & 0.125 & 2.796 & 0.004 \\
Origin & 0.020 & 0.211 & 0.004 & 0.097 & 0.923 \\
Computer self-efficacy & 0.121 & 0.065 & 0.106 & 1.851 & 0.068 \\
Performance expectations & 0.384 & 0.095 & 0.356 & 4.053 & 0.001 \\
System functionality & 0.126 & 0.091 & 0.098 & 1.383 & 0.170 \\
Content features & -0.002 & 0.083 & -0.001 & -0.021 & 0.984 \\
Interactions & 0.141 & 0.076 & 0.110 & 1.843 & 0.069 \\
Learning climate & 0.391 & 0.095 & 0.367 & 4.135 & $<0.001$ \\
\hline
\end{tabular}

$\beta$, unstandardized coefficient; $\mathrm{SE}_{\mathrm{B}}$, standard error of the coefficient; $\mathrm{B}$, standardized coefficient; $t$, $\mathrm{t}$-statistic; $p$, significance level.

functionality and content features were also positively correlated with learner satisfaction. The overall internal consistency of the survey items was 0.97 , while Cronbach's alpha values for all seven domains ranged from 0.83 to 0.96 .

The median rating for students' satisfaction with BIL was 4.63 (interquartile range $[\mathrm{IQR}]=3$ ). System functionality had the highest rating (median $=6, \mathrm{IQR}=1.6$ ) and interactions had the lowest rating (median $=2.5$, $\mathrm{IQR}=2.3$ ). Ratings for the other constructs were as follows: computer self-efficacy (median $=5.3, \mathrm{IQR}=1.6$ ), performance expectations (median $=5.0, \mathrm{IQR}=2.3$ ), Content features (median $=5.5, \mathrm{IQR}=1.9)$, and learning climate (median $=5.0, \mathrm{IQR}=2.3$ ). Male students reported significantly higher computer self-efficacy (median $=$ $5.7, \mathrm{IQR}=1.3$ vs. median $=5.0, \mathrm{IQR}=2.7$; Mann-Whitney $\mathrm{U}=762.50, p=0.031)$ and overall learner satisfaction rates $($ median $=5.5, \mathrm{IQR}=2.5$ vs. median $=3.75, \mathrm{IQR}=$ 3.4; Mann-Whitney $\mathrm{U}=717.50, p=0.012$ ) compared to their female counterparts. There were also significant age group differences in relation to system functionality with higher ratings by the older students (median $=7.0, \mathrm{IQR}=$ 1.3 vs. median $=6.0, \mathrm{IQR}=1.7$; Mann-Whitney $\mathrm{U}=$ $392.50, p=0.013$ ). However, learner satisfaction was not affected by age status (domestic vs. international students). Gender, performance expectation and learning climate were identified as significant predictors of learner satisfaction (Table 2). The results suggest that $87.1 \%$ (adjusted $\left.R^{2}=87.1 \%, F=61.3, p<0.001\right)$ of the learner satisfaction variance can be explained by gender, Performance expectation, and learning climate.

To answer our second research question (what are learners' perceptions of the impact of BIL on their learning

Factors Influencing Blended E-Learning process?), the participants were asked to comment on their experience with BIL, particularly the things that worked well and the areas that they thought would need improvement. Data analysis of the open-ended survey responses identified two emerging themes: improved quality of learning and loss of sense of community. The participants felt "the most obvious advantage was the midvideo quizzes which would help you consolidate and utilise the information presented." They also appreciated the BIL method because the integrated case-based learning approach aided consolidation of learning and provided them with various sources of learning, while the on-line delivery allowed them to learn at their own pace.

"Advantage was that you could learn the content this week by exploring the physiology, pathophysiology and treatment together. Also the quizzes during the video ensured that you were actually engaging with the content being delivered." "Much more organised approach in comparison to the week on anaemia, material presented in a way that is understandable, can work through material at [your] own pace, makes content easier to understand and includes clinical focus/application."

Participants reported that the interactive video quizzes and the ability to play and pause the recording at will also fostered flexible learning opportunities. They also reported that BIL enhanced their critical thinking skills and academic performance. Although the participants felt that more dedicated study time was required for BIL, they appreciated the fact that it fostered deeper learning - "increased time to do BIL (took me $4 \mathrm{~h}$ ) but deeper learning, so worth it."

Nonetheless, the participants reported that BIL encouraged isolated learning and they "did not like the lack 
of interaction with lecturers and students." The reduced social communication with peers and interaction with the lecturers also made it difficult to ask questions in real time and obtain effective feedback on their learning. The participants suggested that interaction could be enhanced through mandatory discussion board chats and provision of clearer learning outcomes. They also asked the lecturers to "still keep GLSs so that students can gain access to tutors and lecturers if they are confused on the content." In relation to the developed learning materials, the participants complained about unnecessary repetitions and the amount of videos provided as they felt compelled to watch them all at once and this was time-consuming.

\section{Discussion}

This study evaluated medical students' satisfaction level and their perceptions of BIL, a teaching method which involved the integration of basic sciences and clinical concepts within a blended learning space; and the study findings indicate that students were generally satisfied with the BIL method. Perceived accomplishment in the learning environment (known as Student satisfaction) is the most important key to life-long learning [18]. Our study demonstrates that performance expectations (cognitive factors) and learning climate (social environment) had an impact on perceived satisfaction in the blended learning space, confirming previous studies [14]. In addition, the students performed better in the post-BIL quiz compared to the post-traditional teaching session quiz, thereby corroborating previous findings that the blended learning approach improves students' academic performance [12].

Male students reported a higher overall learner satisfaction than their female counterparts, which may be partly related to higher levels of computer self-efficacy and reduced anxiety in males compared to females. This finding validates previous literature, which reported that lower perceived computer self-efficacy and higher computer anxiety among female students have an impact on their perceived satisfaction with blended learning [1921]. Females are considered to be more of read/write learners, and they prefer learning environments that encourage communication and collaboration, while males are more kinaesthetic learners who prefer to have practical experiences [22]. Possibly, the loss of community in the blended learning approach used in this study may have influenced the female students' perceptions of satisfaction with BIL [23]. Providing technology-related in- troductory training sessions prior to utilising blended learning approaches and ensuring a sense of community (interactive online sessions) may enhance computer selfefficacy and communication, thereby improving the effectiveness of this learning method [24].

In this study, participants' perceptions about their learning experience demonstrated that BIL is a learnercentred model, which puts the learner in control of their learning, and also enhances clinical integration, application, and retention of knowledge, confirming the results of other studies where learners felt that they had learnt key course concepts better than in the traditional face-toface sessions [25]. Additionally, BIL allowed the students to access the content material at their own pace and in their own time and location, thereby giving the learners the opportunity to effectively manage their work-life balance [26].

Nevertheless, a major social environmental factor that had a negative impact on learners' satisfaction and experience of BIL was the reduced interaction time between the students, their peers, and the lecturers. The participants felt the BIL method did not give them the opportunity to ask questions about content that was confusing. Previous research posits that technology is a useful collaborative and learning tool, but lack of interaction can cause frustration and a sense of isolation [27]. Social interaction in the e-learning space fosters a sense of community and stimulates learning $[15,28]$. To improve on-line peer interactions, participants suggested increased emphasis on discussion board chats, wikis, and blogs as highlighted by previous research [29]. It is also important for educators to apply the right balance in creating on-line learning materials as this will foster student engagement and enhanced learning experience. Furthermore, better understanding of the influence of different learning styles will enable educators to effectively design BIL strategies that meet their students' learning needs [22].

This study was limited to Year-2 medical students; obtaining perspectives from the other pre-clinical years (1 and 3) may elicit different types of experiences. In addition, we only considered students' perceptions of the BIL and did not compare the students' perceptions of BIL to traditional face-to-face teaching, although comparison of students' scores in the on-line quizzes showed better performance after the BIL session. Furthermore, only $50 \%$ of the cohort participated in the survey; nonetheless, comparison of the participants' profile to the cohort showed that they were representative of the cohort. 


\section{Conclusions}

With technological advancement, the future offers the promise of high fidelity, high-speed simulations, and personalised instruction using collaborative blended learning. Wider integration of BIL into pre-clinical undergraduate medical education would further promote the shift towards competence-based education and life-long learning among medical students, wherein educators no longer serve solely as distributors of content, but become facilitators of learning. However, effective implementation of BIL would depend largely on student characteristics, the environmental, and cognitive components of the delivery method. Ensuring that social interactions and communication is maintained through either early introduction of the face-to-face component or with interactive online tools during BIL is important.

\section{Acknowledgements}

The authors acknowledge the support of the IT staff who assisted with the development of the videos and on-line lectures. The authors also thank all students who participated in the study.

\section{Statement of Ethics}

Ethics approval for this study was obtained from James Cook University's Human Research Ethics Committee. Informed consent was obtained from the students who participated in the study.

\section{Disclosure Statement}

The authors declare that they have no conflicts of interest to disclose.

\section{Funding Sources}

This research did not receive any specific grant from funding agencies.

\section{Author Contributions}

All authors contributed equally to the study concept, design, data collection, data analyses, and writing of the paper. All authors read and approved the manuscript for submission.

\section{References}

1 Schauber SK, Hecht M, Nouns ZM, Dettmer $\mathrm{S}$. On the role of biomedical knowledge in the acquisition of clinical knowledge. Med Educ. 2013 Dec;47(12):1223-35.

2 Malau-Aduli BS, Lee AY, Cooling N, Catchpole $\mathrm{M}$, Jose $\mathrm{M}$, Turner R. Retention of knowledge and perceived relevance of basic sciences in an integrated case-based learning (CBL) curriculum. BMC Med Educ. 2013 Oct;13(1):139.

3 McCoy L, Pettit RK, Kellar C, Morgan C. Tracking active learning in the medical school curriculum: a learning-centered approach. J Med Educ Curric Dev. 2018 Mar;5: 2382120518765135.

4 Leung WC. Competency based medical training: review [review]. BMJ. 2002 Sep; 325(7366):693-6.

5 McCoy L, Pettit RK, Lewis JH, Bennett T, Carrasco N, Brysacz S, et al. Developing technology-enhanced active learning for medical education: challenges, solutions, and future directions. J Am Osteopath Assoc. 2015 Apr; 115(4):202-11.

6 Ruiz JG, Mintzer MJ, Leipzig RM. The impact of E-learning in medical education. Acad Med. 2006 Mar;81(3):207-12.

7 Gray K, Tobin J. Introducing an online community into a clinical education setting: a pilot study of student and staff engagement and outcomes using blended learning. BMC Med Educ. 2010 Jan;10(1):6.
8 Asiry MA. Dental students' perceptions of an online learning. Saudi Dent J. 2017 Oct;29(4): 167-70.

9 Lewis SK, Thompson P. Application of Adult Learning Theory to Physician Assistant Education. J Physician Assist Educ. 2017 Dec; 28(4):196-200

10 Green RA, Whitburn LY. Impact of introduction of blended learning in gross anatomy on student outcomes. Anat Sci Educ. 2016 Oct; 9(5):422-30.

11 Street SE, Gilliland KO, McNeil C, Royal K. The Flipped Classroom Improved Medical Student Performance and Satisfaction in a Pre-clinical Physiology Course. Med Sci Educ. 2015;25(1):35-43.

12 Elmer SJ, Carter KR, Armga AJ, Carter JR. Blended learning within an undergraduate exercise physiology laboratory. Adv Physiol Educ. 2016 Mar;40(1):64-9.

13 Chen IS. Computer self-efficacy, learning performance, and the mediating role of learning engagement. Comput Human Behav. 2017;72:362-70.

$14 \mathrm{Wu} \mathrm{JH}$, Tennyson RD, Hsia TL. A study of student satisfaction in a blended e-learning system environment. Comp Educ. 2010; 55(1):155-64.
15 So HJ, Brush TA. Student perceptions of collaborative learning, social presence and satisfaction in a blended learning environment: relationships and critical factors. Comp Educ. 2008;51(1):318-36

$16 \mathrm{Wu} \mathrm{JH}$, Tennyson RD, Hsia TL, Liao YW. Analysis of E-learning innovation and core capability using a hypercube model. Comput Human Behav. 2008;24(5):1851-66.

17 Strauss AL, Corbin JM. Basics of qualitative research: techniques and procedures for developing grounded theory. 2nd ed. Thousand Oaks: Sage Publications; 1998.

18 Sinclaire JK. Student satisfaction with online learning: lessons from organizational behavior. Res High Educ. 2011;11:1.

19 Dang Y, Zhang Y, Ravindran S, Osmonbekov T. Examining Student Satisfaction and Gender Differences in Technology-Supported, Blended Learning. JISE. 2016;27(2):119.

20 Broos A. Gender and information and communication technologies (ICT) anxiety: male self-assurance and female hesitation. Cyberpsychol Behav. 2005 Feb;8(1):21-31.

21 He J, Freeman LA. Are Men More Technology-Oriented than Women? The Role of Gender on the Development of General Computer Self-Efficacy of College Students. JISE. 2010;21(2):203-12. 
22 Ojeh N, Sobers-Grannum N, Gaur U, Udupa A, Majumder MA. Learning style preferences: A study of pre-clinical medical students in Barbados. J Adv Med Educ Prof. 2017 Oct; 5(4):185-94.

23 Nilsson M, Östergren J, Fors U, Rickenlund A, Jorfeldt L, Caidahl K, et al. Does individual learning styles influence the choice to use a web-based ECG learning programme in a blended learning setting? BMC Med Educ. 2012 Jan;12(1):5.
24 Durndell A, Haag Z. Computer self efficacy, computer anxiety, attitudes towards the Internet and reported experience with the Internet, by gender, in an East European sample. Comput Human Behav. 2002;18(5):521-35.

25 Chen WS, Yao AYT. An empirical evaluation of critical factors influencing learner satisfaction in blended learning: A pilot study. Univers J Educ Res. 2016;4(7):1667-71.

26 George-Walker LD, Keeffe M. Self-determined blended learning: a case study of blended learning design. High Educ Res Dev. 2010;29(1):1-13.
27 Harper B. Technology and Teacher-Student Interactions: A Review of Empirical Research. J Res Technol Educ. 2018 Apr;50(1):1-12.

28 Eagleton S. An exploration of the factors that contribute to learning satisfaction of firstyear anatomy and physiology students. Adv Physiol Educ. 2015 Sep;39(3):158-66.

29 Gulbahar Y, Madran RO. Communication and Collaboration, Satisfaction, Equity, and Autonomy in Blended Learning Environments: A Case from Turkey. Int Rev Res Open Dis. 2009 Apr;10(2):2. 